\title{
RAZÃO INSTRUMENTAL E INDÚSTRIA CULTURAL
}

\author{
Ely Guimarães dos Santos Evangelista*
}

\section{RESUMO}

Este texto enfoca a razão instrumental e a indústria cultural, sob a perspectiva de Adorno e Horkheimer, expressa em Dialética do esclarecimento e Eclipse da razão. Neles, os autores se recusam a compactuar com a idéia corrente que confirma o caos cultural em que se enreda o mundo da cultura administrada, cujos espaços são invadidos pela racionalidade técnica da indústria. Para esses autores, a arte paralisa a sua força inovadora ao sucumbir à técnica. Assim, a indústria cultural faz da cultura uma produção em série, condenando os homens à estereotipia.

Palavras-chave: razão instrumental, indústria cultural, racionalidade, estereotipia.

A compreensão dos temas razão instrumental e indústria cultural, da perspectiva teórica de Adorno e Horkheimer, é o que proponho apresentar aqui. Trata-se de uma leitura dos autores, de um exercício intelectual, para o qual tomo como ponto de partida uma questão relativa ao princípio norteador da crítica de Adorno e Horkheimer à racionalidade técnica da indústria cultural. Entendendo o termo princípio como premissa básica, originária, ou seja, aquela que não só funda, mas também orienta o conhecimento elaborado pelos autores, a exposição vai se ater às seguintes questões: Qual é

* Professora da Faculdade de Educação da Universidade Federal de Goiás. [e-mail: ege@terra.com.br] 
esse princípio? Como, movendo o pensamento deles, esse princípio se desdobra?

A delimitação e a finalidade expostas acima justificam estabelecer um recorte e limitar a leitura proposta a dois textos: Dialética do esclarecimento, texto elaborado pelos dois autores, e Eclipse da razão, de Horkheimer, ambos escritos logo após o término da Segunda Guerra Mundial. O primeiro foi publicado em início de 1947 e o segundo, um ano antes. Escritos, portanto, no período em que os autores estavam emigrados nos Estados Unidos, centro mais avançado do modelo de sociedade em cuja crítica eles se empenhavam desde a década de $1920 .^{1}$

Os dois textos foram elaborados num período em que a expressão totalitária do capitalismo e o confronto armado com o sistema internacional e seus aliados resultaram na destruição de parte significativa do Velho Mundo. Tanto neste como no Novo Mundo, milhares de vidas humanas haviam sido ceifadas e foram produzidos outros tantos de mutilados.

O panorama catastrófico explica por si só o tema que une os dois textos: a crítica da razão iluminista, que, na análise dos autores, está na origem mesma do irracional produzido pelos homens na história. Erigida como elemento de emancipação da vida do homem pelas possibilidades de desenvolvimento da produção da tecnologia e do progresso por ela propiciado, a razão iluminista torna-se instrumento e, instalando-se desde a ciência moderna positivista até as demais dimensões da totalidade do social - economia, política, arte, cultura, literatura etc. -, produz o inverso do que se propõe. Não a razão, mas a irracionalidade; não o progresso, mas a regressão; a individualização, e não a individuação; a submissão, alienação, reificação, e não a emancipação do homem.

Esse é o contexto que movia os autores para a elaboração teórica que lhes permitia, em suas palavras no prefácio à Dialética do esclarecimento, datado de maio de 1944, "descobrir por que a humanidade, em vez de entrar em um estado verdadeiramente humano, está se afundando em uma nova espécie de barbárie" (ADORNo; HoRKHEIMER, 1991, p. 11). Referem-se aí aos horrores do nazifascismo, cujo final já se podia, então, antever. Sua derrota, um ano depois, 
impunha "aos povos das nações democráticas, o problema de completar a vitória obtida pelas armas: [...] elaborar e pôr em prática os princípios de humanidade em nome dos quais foram feitos os sacrifícios da guerra".

Nesse momento, apresentando ao público leitor seu livro Eclipse da razão, Horkheimer reafirma, no prefácio de 1946, a preocupação com a idéia "de uma sociedade verdadeiramente humana", ainda ausente, com a aparente redução que pareciam ter sofrido "a autonomia do homem enquanto indivíduo, a sua capacidade de opor resistência ao crescente mecanismo de manipulação das massas, o seu poder de imaginação e o seu juízo independente". Expressa, portanto, sua preocupação com o "processo de desumanização", enfim, com a ameaça, pelo progresso, à anulação daquilo "que se supõe ser o seu próprio objetivo: a idéia de homem" (HORKHEIMER, 1976, p. 5-6).

Quase duas décadas após, nova expressão dos autores incide sobre os mesmos temas. Desta vez é no prefácio à nova edição alemã da Dialética do esclarecimento, escrito em 1969. A possibilidade permanente de colisão dos dois grandes blocos em que se dividiu o mundo após a derrota do nazismo, e, no seu todo, a situação econômica e política do mundo sob essa ameaça evidenciam a continuidade do horror e provocam a afirmação de que

[...] o pensamento crítico, que não se detém nem diante do progresso, exige hoje que se tome partido pelos últimos resíduos de liberdade, pelas tendências ainda existentes a uma humanidade real, ainda que pareçam impotentes em face da grande marcha histórica. (ADORNo; HORKHEIMER, 1991, p. 9)

De fato, anunciam-se nesses prefácios, como elemento comum, que permeia os dois textos, a idéia do humano, sua realização nos homens mediante a emancipação do indivíduo, sua liberdade, sua realização social, potencialidades cuja atualização o progresso permite vislumbrar e, ao mesmo tempo, paradoxalmente, impede de realizar. Esse é o dilema que se erige, nos dois textos, como fundante da elaboração teórica neles exposta, isto é, como princípio originário, mas que também impulsiona e alimenta o pensamento crítico. Este 
deve, então, se debruçar sobre o conceito de razão, cuja realização na história resultou na aporia progresso-regressão, e, compreendendoa de dentro, liberar a utopia nela contida e não realizada: "a utopia de uma humanidade que, não sendo mais desfigurada, não precisa mais de desfigurar o que quer que seja" (Adorno; HorkHEIMER, 1991, p. 112). A filosofia que "não pode determinar se deve predominar no futuro a tendência barbarizante ou a visão humanística" pode,

[...] ao fazer justiça àquelas imagens e idéias que em determinadas épocas dominaram a realidade [...] e que foram abandonadas no curso da História, assumir sua função crítica e, [...] assumindo tal função [a filosofia] [...] seria a memória e a consciência da espécie humana e, deste modo, ajudaria a evitar que a marcha da humanidade se assemelhasse à circulação sem sentido na hora de recreio de um manicômio. (HoRKHEIMER, 1976, p. 197-198)

\section{INSTRUMENTALIZAÇÃO DA RAZÃO}

A formalização, instrumentalização, coisificação da razão constituem o tema central e recorrente no pensamento de Adorno e Horkheimer nos dois textos aqui considerados. Na Dialética do esclarecimento, os autores, valendo-se especialmente do mito, traçam a trajetória da razão na história, incluindo o passado pré-histórico, evidenciando a tensão permanente entre mito e razão. Em Eclipse da razão, Horkhemeir recorre fundamentalmente à história da filosofia para discutir o processo de subjetivação, formalização, instrumentalização da razão. Mas a interlocução fundamental em ambos é, em última instância, com o positivismo em suas diversas versões, o qual, em suas origens, marca um momento forte de inflexão da razão esclarecida em seu retorno ao mito.

A Dialética do esclarecimento inicia-se com a afirmação da aporia em que se enreda o mundo esclarecido. O objetivo do pensamento de que este se constitui é o de libertar os homens da ignorância e do medo e, dessa forma, permitir-lhes o domínio do mundo. Assim, o saber que é poder, como bem profetizou Bacon, "deve imperar sobre a natureza desencantada". E para isso o saber "não conhece barreira". Ligando-se desde sua origem ao domínio da 
natureza, a razão se faz técnica a serviço do capital e escraviza os homens. A meta do esclarecimento é eliminar a superstição, "dissolver os mitos e substituir a imaginação pelo saber" (ADORNO; HORKHEIMER, 1991, p. 19). Assim a "idéia absoluta", igualada aos mitos e à imaginação, é também excluída do saber. "No trajeto para a ciência moderna, os homens renunciaram ao sentido e substituíram o conceito pela fórmula, a causa pela regra e pela probabilidade" (ADORNO; HoRKHEIMER, 1991, p. 21). Recusando tudo o que não se enquadra nos critérios de cálculo e utilidade, a ciência moderna positivista busca o método para trabalhar o emaranhado do mundo factual a ser ordenado, classificado, unificado pela lógica formal e traduzido pela matemática e, dessa forma, permite a explicação, a previsão e o controle.

Entretanto, segundo os autores, estabeleceu-se, assim, a mitologização do pensamento que se queria esclarecido. Isso se demonstra pela análise da genealogia desse pensamento que, da magia ao esclarecimento da sociedade burguesa, passando pela mitologia, religião e filosofia, revela um caminhar semelhante: a eliminação das distinções, a unificação do que é múltiplo e, por essa via, o domínio pelo sujeito que, semelhante a Deus, subordina, pelo saber, a natureza da qual se distingue e da qual se aliena.

Atingindo essa distinção, a única admitida pela razão esclarecida, Adorno e Horkheimer comparam o esclarecimento e a magia, de um lado, à identidade do sujeito, e, de outro, à natureza, à matéria, ao objeto do conhecimento, para oporem, a esse modo de ser da razão, a multiplicidade, as distinções presentes nos rituais mágicos que, nesse sentido, parecem mais flexíveis que o rígido ritual adotado pela razão formalizada e matematizada. Assim, no ritual mágico, que não se nega enquanto dominação,

[...] o feiticeiro torna-se semelhante aos demônios; para assustálos ou suavizá-los ele assume um ar assustadiço ou suave [e] embora seu ofício seja a repetição [...] ainda não se declarou à imagem e semelhança do poder invisível. (ADORNo; HoRKHEIMER, 1991, p. 24)

Mantendo vários dos princípios da magia e do mito, o esclarecimento, ao eliminar o incomensurável, ao proceder à unidade 
conceitual e à autonomia do pensamento em relação aos objetos, elimina também o conceito como aquilo que foi, desde suas origens, "produto do pensamento dialético no qual cada coisa só é o que ela é tornando-se aquilo que ela não é". Ou seja, o esclarecimento radicaliza a negação da contradição, subsumida ao princípio da identidade, ao longo da trajetória da razão, desde a superação das antigas representações difusas da magia, passando pela captura do ser pelo logos, por sua redução à mônada e por sua negação pela razão esclarecida.

Nesses diferentes momentos da trajetória da razão ocidental, os autores relacionam suas formas de expressão à sociedade e, nesta, às relações de dominação e submissão da natureza e dos homens, concluindo que "a forma dedutiva da ciência reflete [...] a hierarquia e a coerção". A isso acrescentam, entrando em interlocução com o pensamento de Durkheim, que

[...] assim como as primeiras categorias representavam a tribo organizada e seu poder sobre os indivíduos, assim também a ordem lógica em seu conjunto [...] baseia-se nas relações correspondentes da realidade social da divisão do trabalho [entendida como] unidade impenetrável da sociedade e da dominação [e não] como expressão da solidariedade. (AdORNO; HORKHEIMER, 1991, p. 34)

Assim, os autores contrapõem à pretensa neutralidade dos achados da ciência e da linguagem, pela qual eles são expressos, a sedimentação, nas formas de pensamento, da dominação e da opressão existentes no todo social, em que o particular realiza-se como universal: na magia, no mito, na metafísica e também no esclarecimento. Querendo se libertar das formas anteriores, o esclarecimento limita-se ao factual, circunscreve a razão ao imediatamente dado e faz do desconhecido a incógnita de uma equação matemática. Assim procedendo, transforma o pensamento em coisa, instrumento que renuncia ao conhecimento, reproduzindo o "mesmo" e abdicando da tarefa de se auto-refletir, já prevista em Kant. Este, combinando a possibilidade de progressão do pensamento com a impossibilidade de alcançar o Ser, sela o destino do pensamento esclarecido que 
[...] resguardado dos sonhos de um visionário nas diversas disciplinas da ciência, recebe a conta: a dominação universal da natureza volta-se contra o próprio sujeito pensante; nada sobra dele senão justamente esse 'eu penso' eternamente igual que tem que poder acompanhar todas as minhas representações. (ADORNo; HORKHEIMER, 1991, p. 38)

As conseqüências dessa dominação permitem detectar a afirmação da idéia postulada no presente estudo como princípio fundante na elaboração teórica dos autores. Segundo eles, o que resulta daquela dominação é não apenas

[...] a alienação dos homens com relação aos objetos dominados; com a coisificação do espírito, as próprias relações dos homens foram enfeitiçadas, inclusive as relações de cada indivíduo consigo mesmo. Ele se reduz a um ponto nodal das reações e funções convencionais que se esperam dele como algo objetivo. O animismo havia dotado a coisa de uma alma, o industrialismo coisifica as almas. (ADORNO; HORKHEIMER, 1991, p. 40)

Denunciando assim a impossibilidade de realização do ideal emancipador do esclarecimento nos quadros do industrialismo, os autores acrescentam à vinculação desse ideal ao domínio da natureza uma outra razão. Por ela, esse domínio resulta também no domínio dos homens que, como o pensamento, são também coisificados. $\mathrm{O}$ caráter fetichista da mercadoria, na sociedade regida pela troca, espalha-se, tal qual a razão instrumental, por todos os espaços sociais, assim como nos comportamentos dos indivíduos.

Nos dois excursos que integram o texto, os autores vão aprofundar a análise da unidade contraditória mito e esclarecimento, explicitando, no primeiro, a dialética das duas expressões da razão e, no segundo, as implicações dos ideais originários de domínio da natureza pelo sujeito para a ciência e a moral constitutivas da sociedade burguesa.

Percorrendo os episódios da Odisséia, de Homero, os autores destacam - da trama dos acontecimentos da epopéia - os conceitos de renúncia e sacrifício e demonstram, à exaustão, o entrelaçamento 
contraditório do esclarecimento e do mito, afirmado nas teses centrais de que se ocupam no texto como um todo. Assim, identificam na epopéia elementos que denotam a presença do esclarecimento no passado mítico, bem como a presença do mito no espírito esclarecido, que se difunde pela sociedade burguesa, seja na sua ordem econômica, ou nas atitudes, capacidades e comportamentos que garantem sua constituição, sua reprodução e legitimação, seja ainda em suas formas jurídicas, suas expressões artísticas, como também na utilidade da linguagem nessa sociedade.

Teorizando sobre os conceitos de renúncia e sacrifício, os autores utilizam-se dos episódios em que Ulisses, a despeito de sua impotência, vence os deuses, figuras míticas e forças da natureza, tomando, dessa forma, consciência de sua identidade. E nas aventuras que enfrenta, safando-se das múltiplas e perigosas seduções, pela renúncia e pelo sacrifício calculado, o herói garante sua autoconservação e o "retorno à pátria e aos bens sólidos" (AdORno; HORKHEIMER, 1991, p. 56).

A outras interpretações correntes do princípio do sacríficio, Adorno e Horkheimer, recorrendo à história, contrapõem a sua teoria e apontam - do totemismo às religiões populares, do mito ao esclarecimento - os componentes que explicam sua racionalidade, real e ilusória, e também sua irracionalidade. Ligando o sacrifício ao domínio de si e do outro e à autoconservação, afirmam a permanência do sacrifício na civilização com consequiências para o sujeito que com ela se mantém idêntico.

$\mathrm{Na}$ história das classes, a hostilidade do eu ao sacrifício incluía um sacrifício do eu, porque seu preço era a negação da natureza no homem, em vista da dominação sobre a natureza extra-humana e sobre os outros homens. [Com isso], não apenas o telos da dominação externa da natureza, mas também o telos da própria vida se torna confuso e opaco. (AdorNo; HorKHEIMER, 1991, p. 60)

Identificando as origens da autoconsciência no domínio do homem sobre si mesmo, os autores explicitam a contradição que o autodomínio encerra: ser, ao mesmo tempo, "a destruição virtual do 
sujeito a serviço do qual ele ocorre", à medida que a compulsão pelo domínio resulta na negação do sujeito, na "introversão do sacrifício" (AdORNO; HORKHEIMER, 1991, p. 61).

Assim, na ligação da razão com o domínio, já preconizada na máxima baconiana, "saber é poder", está inscrita a contradição na e pela qual a razão expressa-se como anti-razão.

A anti-razão do capitalismo totalitário, cuja técnica de satisfazer as necessidades, em sua forma objetualizada, determinada pela dominação, torna impossível a satisfação das necessidades e impele ao extermínio dos homens - essa anti-razão está desenvolvida de maneira prototípica no herói homérico que se furta ao sacrifício sacrificando-se. A história da civilização é a história da introversão do sacrifício. Ou por outra, a história da renúncia. (ADORNo; HoRKHEIMER, 1991, p. 61)

A crítica dos autores à razão como instrumento que, erigindo o meio como fim, tem suas origens na pré-história da civilização ocidental, teria o sentido de uma negação da razão esclarecida, no reino da qual não há lugar para o homem em sua essência humana?

Uma resposta a essa questão pode ser fundamentada em passagens do excurso em que o mito, fazendo-se esclarecimento, manifesta-se em sua dupla e contraditória dimensão. Assim, o Ulisses, cujo sacrifício

[...] deixa escapar a vida, [...] é ao mesmo tempo uma vítima que se sacrifica pela abolição do sacrifício. Sua renúncia senhoril é, enquanto luta com o mito, representativa de uma sociedade que não precisa mais da renúncia e da dominação: que se tornou senhora de si, não para fazer violência a si mesma e aos outros, mas para a reconciliação. (ADORNO; HORKHEIMER, 1991, p. 61)

Com freqüência, ao longo desse excurso, ao derivar dos episódios descritos, remetendo os elementos de dominação à sociedade burguesa, os autores estabelecem a ligação com a barbárie em que esta derivou na expressão nazifascista, com a qual o mundo defrontava-se no momento em que o ensaio foi produzido. 
A linguagem, carregada de sentimento, revela-se no estilo da narrativa e na contundência da análise e da crítica radical e ferina referidas aos sofrimentos a que os homens estavam sendo submetidos.

Talvez, por isso, a leitura possa apontar para um ceticismo em relação à razão. Em outros momentos, quando se ressaltam, na unidade do mito e do esclarecimento, as diferenças entre ambos, sugerindo que o esclarecimento é uma reedição piorada do mito, podem apontar ainda para um nostálgico sentimento de retorno a um passado que, em sua irracionalidade, foi mais racional que o presente vivido.

Entretanto, principalmente, ao final desse excurso, o episódio em que Ulisses, para aplacar a fúria de Posêidon, deve chegar à terra dos homens que não conhecem o mar, carregando um remo sobre o ombro, Adorno e Horkheimer apontam para outra conclusão. Em sua interpretação, o equívoco do remo, tomado como pá, provocaria em Posêidon uma gargalhada que dissiparia sua raiva. Deduzindo desse episódio o duplo sentido do riso - com o qual a natureza cega toma consciência de si mesma, privando-se assim da violência destrutiva -, os autores relacionam-no à promessa da pátria em oposição ao mito. "O riso está ligado à culpa da subjetividade, mas, na suspensão do direito que ele anuncia, também aponta para o fim da servidão. Ele promete o caminho da pátria" (ADORNo; HORKHEIMER, 1991, p. 78). Lembrando que é a saudade de casa que leva Ulisses em suas aventuras a escapar do mundo primitivo, os autores remetem ao que o nazismo fantasiava da pátria e da oposição do conceito de pátria ao mito, "paradoxo mais profundo da epopéia", argumentam e concluem:

É aí que se encontra sedimentada a lembrança da passagem histórica da vida nomádica à vida sedentária, que é o pressuposto da existência de qualquer pátria. Se é na ordem física da propriedade dada com a vida sedentária que se origina a alienação dos homens, de onde nasce a nostalgia e a saudade do estado originário perdido, é também na vida sedentária [...] e na propriedade fixa apenas que se forma o conceito da pátria, objetivo de toda nostalgia e saudade. (ADORNo; HoRKHEIMER, 1991, p. 78) 
E, aludindo à definição "segundo a qual a filosofia é nostalgia", os autores a admitem como correta somente sob a condição de que a nostalgia não se resolva "no fantasma de um antiquíssimo estado perdido" mas represente "a pátria [...] como algo extraído ao mito [...] como o estado de que escapou" (Adorno; HorkHeIMER, 1991, p. 78).

No excurso II, os autores tomam como referências Kant, Sade e Nietszche para, aprofundando a tese central do ensaio, extrair consequiências do domínio da natureza pela razão, posta no sujeito autocrático, gerando as aporias de uma ciência que se quer objetiva e de uma moral que se expressa no seu inverso.

O idealismo transcendental kantiano constitui-se na síntese e na legitimação do ideal de autoconservação já posto em prática pela razão esclarecida submetida à fórmula ditada pelo mercado. Partindo do existente, do indubitável, da física e da matemática, Kant expõe, na harmonia do sistema regido pelas leis lógicas, o poder da razão de conduzir o homem à maioridade. Prevê a harmonia entre o sistema $\mathrm{e}$ a natureza e, portanto, a possibilidade de, pelo entendimento, pelo esquematismo da razão pura, produzir uma "ordem científica unitária e a derivação do conhecimento factual a partir de princípios" (ADORNO; HorkHeIMER, 1991, p. 81). Kant não prevê, entretanto, aquilo que se esconde por trás da postulada clareza dos juízos: os sujeitos lógicos do esclarecimento, que supostamente se uniriam ao ego transcendental, "se encontram em oposição uns aos outros" (ADORNo; HorkHEIMER, 1991, p. 83).

A solidariedade consciente do todo sucumbe, e com ela a utopia do sujeito universal, sob a razão calculadora que, livre do seu sentido, ganha o sentido que lhe confere a autoconservação a cuja finalidade a razão se liga.

Refazendo o caminho da razão e irrazão, os autores ressaltam que, na busca da ciência unitária, o sujeito universal não se concretizou:

[...] com a confirmação do sistema científico como figura de verdade [...] o pensamento sela sua própria nulidade, pois a ciência é um exercício técnico, tão afastado de uma reflexão sobre seus próprios fins como o são as outras formas de trabalho sob a pressão do sistema. (ADORNo; HORKHEIMER, 1991, p. 84) 
A impossibilidade de derivar uma doutrina moral consistente com as teorias filosóficas, na sociedade em que a ciência, confirmada pela filosofia como verdade, se faz instrumento, mantém vivo o "horror que inspira a regressão à barbárie [...], raiz do otimismo kantiano, segundo o qual o agir moral é racional mesmo quando a infâmia tem boas perspectivas" (AdORNo; HORKHEIMER, 1991, p. 85).

Sade e Nietsche são apresentados como críticos da razão prática, na medida em que, na filosofia de ambos, o sujeito, salvo da minoridade pelo entendimento kantiano, mostra-se livre de toda tutela, como o burguês sem máscaras, voltado para a autoconservação. Isto é demonstrado por Adorno e Horkheimer quando relacionam as vivências dos personagens de Sade com o pensamento de Sade e Nietzsche e destes com Kant. Pontos de convergência e oposição são então analisados na sua relação com a sociedade burguesa.

Assim, Juliette traduz o autodomínio preconizado na idéia de virtude de Kant (para quem a moral é racional), na dissertação que faz sobre a autodisciplina do criminoso que, livre de qualquer remorso, deve revelar calma em sua fisionomia:

Primeiro imagine seu plano com vários dias de antecedência, reflita sobre todas as consequiências, examine com atenção o que poderá lhe ser útil [...] o que será susceptível de traí-la [a autodisciplina] [...] faça reinar nela [a fisionomia] a calma e a indiferença e trate de adquirir o maior sangue-frio possível nessa situação [...]. (SADE apud Adorno; HorKHEIMER, 1991, p. 93)

De forma similar, Nietzsche (apud AdORNo; HoRKHEIMER, 1991, p. 94) traduz a filantropia kantiana, estabelecendo como "primeira proposição de "nossa' filantropia que os fracos e os malformados devem perecer [...]".

O que Adorno e Horkheimer demonstram, através de Nietzche e Sade, é a expressão da regressão e da barbárie, sob a qual o indivíduo sucumbe na sociedade em que o entendimento, liberto do mito, da imaginação e da filosofia, produz a ciência calculadora e niveladora.

Através de Nietzsche e Sade, "os escritores sombrios da burguesia", Adorno e Horkheimer, explicitam as conseqüências do 
esclarecimento, ocultadas nas doutrinas harmonizadoras dos "escritores luminosos" da mesma burguesia (ADORNO; HORKHEIMER, 1991, p. 111), na concretização da lei do mais forte, na desumanização e irrazão em que se transformaram as instituições, a moral, as relações entre os indivíduos e destes consigo mesmos, enfim, os sentimentos da sociedade que, pela subjetivação da razão, elimina o sujeito.

O fato de ter, não encoberto, mas bradado ao mundo inteiro a impossibilidade de apresentar um argumento de princípio contra o assassinato ateou o ódio com que os progressistas ainda hoje perseguem Sade e Nietzsche. [...] Ambos tomaram a ciência ao pé da letra. $\mathrm{O}$ fato de que insistem na ratio de uma maneira ainda mais decidida do que o positivismo tem o sentido concreto de libertar de seu invólucro a utopia contida, como no conceito kantiano, em toda grande filosofia: a utopia de uma humanidade que, não sendo mais desfigurada, não precisa mais de desfigurar o que quer que seja. (AdORNO; HoRKHEIMER, 1991, p. 112)

Portanto, se Adorno e Horkheimer recorreram à expressão brutal da verdade chocante é porque reconhecem a obra de Sade como "uma alavanca para salvar o esclarecimento" (1991, p. 111), e, na recusa de Nietzsche à compaixão, a possibilidade de salvar "a confiança inabalável no homem, traída a cada vez que se faz uma afirmação consoladora" (ADORNO; HORKHEIMER, 1991, p. 113).

\section{A INDÚSTRIA CULTURAL}

A formalização da razão em grau extremo é evidenciada por Adorno e Horkheimer no segmento do texto intitulado "A indústria cultural: o esclarecimento como mistificação das massas", no qual, descrevendo aspectos reveladores da difusão globalizadora e niveladora da razão instrumental, ressaltam o fato de que a racionalidade característica da civilização atual confere a tudo um ar de semelhança. Perpassando as diversas partes do sistema, ela torna manifesto o seu caráter de identidade, unidade e coesão. Assim, os autores contrapõem-se à interpretação corrente que confirma o caos cultural do mundo industrial, no qual tudo se submete à racionalidade 
técnica dos setores mais poderosos da indústria. Invadindo também a produção dos bens culturais, essa racionalidade técnica torna-se inerente aos monopólios culturais, cujos produtos circunscrevem-se no mesmo esquematismo da produção em geral e, como os demais, transformam-se em valor de uso para o consumidor e valor de troca para o produtor.

Dessa forma, a racionalidade técnica cumpre sua função econômica na cultura administrada. A partir da reprodutibilidade mecânica de bens culturais padronizados, o progresso técnico vai costurando, mediante diversos setores - rádio, cinema, revistas -, a coesão e a unidade do sistema. Sob o pretenso atendimento ao gosto do consumidor, promove-se seu nivelamento, sua normalização e padronização - ditados pelos setores mais poderosos da indústria, aos quais se submete a indústria cultural -, recalcando, "pelo controle da consciência individual [...], a necessidade que talvez pudesse escapar ao controle central" (ADORNO; HORKHEIMER, 1991, p. 114).

Dessa submissão resulta a identidade dos bens culturais com aqueles produzidos pelos diferentes setores técnicos da esfera global da produção. Como mercadoria, os produtos culturais, sob o pretenso atendimento ao gosto dos consumidores, promovem seu nivelamento, sua identificação com a civilização que os produziu. Para isto, os monopólios culturais fazem do consumidor um elemento do próprio sistema, a partir do qual a cultura é administrada, quantificando-o, classificando-o por níveis, aos quais são distribuídos os produtos culturais aparentemente diferenciados, destinados, de fato, a promover a conformidade de cada um com o nível em que foi classificado.

$\mathrm{Na}$ verdade, essa diferenciação dos produtos é ilusória. Sua unidade é garantida pelo esquematismo da produção em série, no qual, como que seguindo um catecismo oficial, a estereotipia é garantida pelos jargões, pela harmonia da palavra, imagem e música, enfim pela combinação dos detalhes ou pelos "clichês prontos para serem empregados arbitrariamente aqui e ali e completamente definidos pela finalidade que lhes cabe no esquema" (ADORNo; HORKHEIMER, 1991, p. 117), do qual resultam produtos culturais que são a repetição do sempre mesmo. "Não somente os tipos de canções de sucesso, os astros, as novelas ressurgem ciclicamente como 
invariantes fixos, mas o conteúdo específico do espetáculo é ele próprio derivado deles e só varia na aparência" (ADORNo; HorkHEIMER, 1991, p. 117).

Dessa forma, o novo, por ser um risco, é eliminado na cultura administrada. Nela nada surge que não tenha sido previsto, nada resta a ser classificado pelo consumidor que é então reproduzido tal qual fora produzido pela sociedade industrial.

Esse resultado é tanto mais eficazmente atingido quanto mais os produtos culturais assemelham-se ao cotidiano do consumidor. É assim que a indústria cultural "exercita o indivíduo no preenchimento da condição sob a qual ele está autorizado a levar essa vida inexorável" (ADORNo; HORKHEIMER, 1991, p. 143).

Mediante uma descrição minuciosa da combinação dos detalhes e efeitos em gêneros diversos de filmes e de música, os autores constroem seus argumentos sobre como aquilo que é imposto aos indivíduos como diversão termina por se destruir. Assim, o que é oferecido como arte termina por fazer com que a arte e a idéia de que ela é portadora sucumbam à técnica, paralisando sua força inovadora. Adorno e Horkheimer referem-se aqui ao sentido da arte nos primórdios da sociedade burguesa, quando a expressão artística era portadora do estilo autêntico que, ao ser transposto pela indústria cultural aos seus produtos, é caricaturado, negado como tal, guardando, entretanto, na sua transparência, uma propriedade já presente no estilo autêntico da obra de arte, no passado burguês: a de exprimir a "estrutura diversificada do poder social" (ADORNo; HORKHEIMER, 1991, p. 122).

Ressaltando o sentido de promessa que o estilo imprime em toda obra de arte, Adorno e Horkheimer explicam que o estilo

[...] não consiste na realização da harmonia - a unidade problemática da forma e do conteúdo, do interior e do exterior, do indivíduo e sociedade -, mas nos traços em que aparece a discrepância, no necessário fracasso do esforço apaixonado em busca da identidade. (Adorno; HorkHEIMER, 1991, p. 123)

É a esse fracasso que a obra medíocre e a indústria cultural, reduzidas ao estilo, renunciaram. Nelas, ao contrário, busca-se a semelhança com as outras, a "imitação como algo absoluto". É a 
barbárie estética consumada no conceito de cultura reduzido a um denominador comum que oculta os múltiplos sentidos e as contradições abarcados pelo termo cultura, em sentido amplo, assim como oculta o enraizamento desses múltiplos sentidos na desigualdade social. Para os autores,

[...] a barbárie estética consuma hoje a ameaça que sempre pairou sobre as criações do espírito desde que foram reunidas e neutralizadas a título de cultura. Falar de cultura foi sempre contrário à cultura. [...] Só a subsunção industrializada e conseqüente é inteiramente adequada a esse conceito de cultura [...] que já contém virtualmente o levantamento estatístico, a catalogação que introduz a cultura no domínio da administração. (ADORNO; HORKHEIMER, 1991, p. 123)

A administração da cultura, que inclui

[...] a idéia de 'esgotar' as possibilidades técnicas dadas, idéia da plena utilização de capacidades em vista do consumo estético massificado, é própria do sistema econômico que recusa a utilização das capacidades quando se trata da eliminação da fome. (ADORNo; HoRKHEIMER, 1991, p. 130)

Nesse processo, a indústria que faz da cultura mercadoria, fundindo-a com a diversão e o entretenimento, expõe os indivíduos a seus produtos e torna-se a apologia da sociedade que impede a realização do humano nos homens. Condenando-os à estereotipia e à resignação, a indústria cultural está sempre a "lograr seus consumidores quanto àquilo que está continuamente a lhes prometer" (ADORNo; HoRKHEIMER, 1991, p. 130). Fazendo da diversão o prolongamento do trabalho mecanizado, reintegra os indivíduos à universalidade falsa, da qual buscam escapar. Produzindo em série o objeto do desejo, excitando o prazer e realizando o seu recalcamento, cada um dos espetáculos dessa indústria "vem mais uma vez aplicar e demonstrar de maneira inequívoca a renúncia permanente que a civilização impõe às pessoas" (AdORNo; HORKHEIMER, p. 132). 


\section{CONSIDERAÇÕES FINAIS}

A pontuação que segue o subtítulo aqui aposto sinaliza a consciência da impropriedade da palavra que a antecede. O momento, de fato, exige uma pausa e não o término.

Certamente, a complexidade de que se reveste a educação na sociedade tecnológica torna-se ainda mais problemática quando se ampliam as fronteiras do mundo e se reduz o tempo entre o acontecimento e a sua difusão administrada, exigindo de fato um permanente repensar dessa prática humana, cuja idade é a mesma do homem e do mundo.

No momento em que se reedita, a partir da década de 1990, o discurso de uma educação tecnificada, ${ }^{2}$ intensificado desde as décadas de 1960 e 1970, as universidades públicas mais uma vez são alvos do chamamento do Ministério da Educação para o enfrentamento do desafio da sociedade em processo de globalização e engajam-se na criação de uma cultura da informática. Atualizam-se em face da sociedade da informação e da cultura da high tech, para viabilizar ao mesmo tempo em que é pauperizada pela lógica da quantidade -o sonho de uma sociedade na qual a educação é abertamente considerada um produto mundial e na qual se justificam os compromissos assumidos pelos governantes nacionais em fóruns mundiais. Renovase aí o otimismo em relação à educação a distância como solução de uma educação ao longo da vida, na seqüência de uma "educação básica para todos", freqüentemente reduzida ao ensino fundamental e obrigatoriamente vinculada "ao mundo do trabalho e à prática social".

Congelam-se, dessa forma, elementos da formação de sujeitos nas mercadorias que vêm atender aos objetivos da "educação" teorizada pelo Banco Mundial, percebida como um produto ou serviço mundial e discutida, juntamente com a comunicação - também reduzida a um serviço - na Organização Mundial do Comércio.

Assim também nas práticas que se querem educativas eliminase a possibilidade do novo na indústria cultural que se expande na direção do campo da educação, edificando a subjetividade requerida pelo mercado. Isto é, o indivíduo que preencha "a condição sob a qual 
ele está autorizado a levar essa vida inexorável" (ADORNo; HoRKHEIMER, 1991, p. 143).

É então que a imagem de eclipse da razão, como título da crítica de Horkheimer à subjetivação da razão, atinge pleno significado: período de obscuridade, desmaio. A razão foge de si própria, foge de sua autoconsciência, oculta sua capacidade de autocompreender-se, demite-se de compreender a realidade humana. E, nessa contingência, as mesmas evidências que nos forçam a admitir com Horkheimer que "a máquina expeliu o maquinista; está correndo cegamente no espaço" (1976, p. 139). Também nos permitem pensar o progresso tecnológico como obra do homem e para o homem, e pensar a tecnologia dele decorrente como recurso de uma educação voltada para o objetivo que deve ser sempre o seu - criar homens felizes numa sociedade justa. Este sim, um desafio que reclama e merece ser enfrentado.

\begin{abstract}
This paper focuses on the instrumental reason and the cultural industry, under the perspective of Adorno and Horkheimer expressed in Dialectic of enlightement and Eclipse of reason. In both of these books, the authors disagree with the current idea which reinforces the cultural chaos, entangled by the world of administrated culture. In it, all the spaces are invaded by the industry technical rationality. To Adorno and Horkheimer, when art succumbs to technic, it looses its innovative power. Thus, the cultural industry makes culture a production in series, condemning men to stereotipy.
\end{abstract}

Key words: instrumental reason, cultural industry, rationality, stereotipy.

\title{
NOTAS
}

1. Em 1923, foi criado o Instituto de Pesquisa Social cuja idéia surge da realização de uma semana de estudos marxistas em 1922 na Turíngia, reunindo um grupo de autores marxistas heterodoxos, entre os quais George Lukács e Karl Korsch. Vinculado à Universidade de Frankfurt, o instituto reunia, quando de sua criação, além de Adorno e Horkheimer, autores como Carl Gruenberg, primeiro diretor, Herbert Marcuse, Erich Fromm e, 
mais tarde, Walter Benjamim e Jurgen Habermas. Em 1933, o instituto foi fechado pelo governo nazista, transferindo-se então para Genebra e, no ano seguinte, para Nova Yorque. Em 1950, ele é transferido para Frankfurt para onde retornam Adorno e Horkheimer (Cf. FreitAG, 1990).

2. Ver a respeito Evangelista (1997).

\section{REFERÊNCIAS}

ADORNO, T. W.; HORKHEIMER, M. Dialética do esclarecimento: fragmentos filosóficos. 2. ed. Rio de Janeiro: Zahar, 1991.

EVANGELISTA, E. G. dos S. Educação e mundialização. Goiânia: Ed. UFG, 1997.

FREITAG, Bárbara. A teoria crítica: ontem e hoje. São Paulo: Brasiliense, 1990.

HORKHEIMER, M. Eclipse da razão. Rio de Janeiro: Editorial Labor do Brasil, 1976.

RECEBIDO EM 04/02/2003

APROVADO EM 03/06/2003 